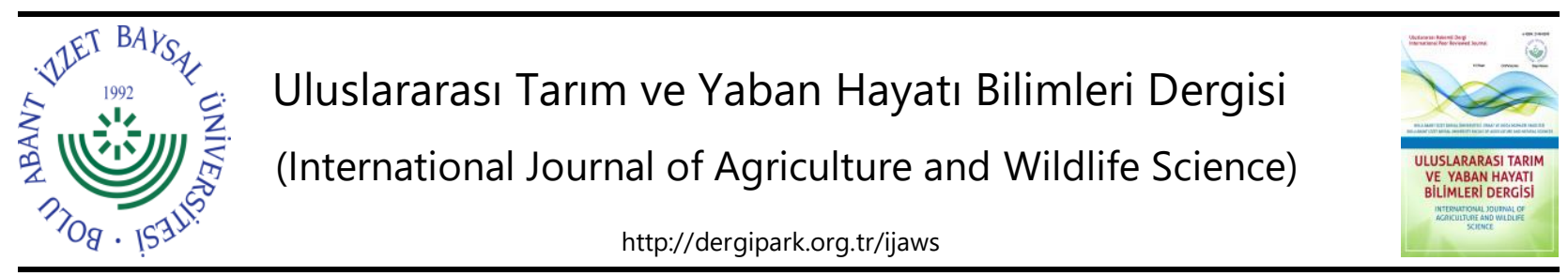

Araştırma Makalesi

\title{
Bolu ili Kiraz ve Vişne Bahçelerinde Belirlenen Zararlı ve Faydalı Türler
}

\author{
Gülay Kaçar*, Abdurrahman Sami Koca
}

Bolu Abant İzzet Baysal Üniversitesi, Ziraat Fakültesi, Bitki Koruma Bölümü, Bolu

Geliş tarihi (Received): 06.05.2020 Kabul tarihi (Accepted): 01.07.2020

\begin{abstract}
Anahtar kelimeler:
Bolu, kiraz, vişne, zararlılar, doğal düşmanlar

*Sorumlu yazar

gulaysahan@yahoo.com

Özet. Kiraz ve vişne, taze ve kuru tüketime sahip ekonomik olarak önemli meyve çeşitleridir. Seben (Bolu), ekolojik özellikleri bakımından meyve üretiminde Bolu'nun en fazla paya sahip ilçesidir. Bu çalışma 2015-2016 yılları arasında Seben ilçesinde bulunan kiraz ve vişne alanlarında bulunan zararlı ve faydalı türleri belirlemek amacıyla yapılmıştır. Örneklemeler mayıs ayından ekim ayı sonuna kadar iki haftada bir kez yapılmıştır. Çalışma sonucunda yedi takıma bağlı 14 familyadan 16 zararlı böcek türü, üç takımdan üç familyaya bağlı yedi faydalı tür belirlenmiştir. Zararlı türlerden Rhagoletis ceraci L. (Diptera: Tephritidae), Myzus cerasi F. (Hemiptera: Aphididae), Drosophila suzukii Matsumura (Diptera: Drosophilidae), Panonychus ulmi Koch ve Tetranychus urticae Koch (Acarina: Tetranychidae) kiraz ve vişne bahçelerinde yaygın türler olarak bulunmuştur. Faydalılardan ise en yaygın türler olarak Stethorus gilvifrons Muls., Stethorus punctillum Weise, Coccinella septempunctata L. (Coleoptera: Coccinellidae) ve Chrysoperla carnea Steph. (Neuroptera: Chrysopidae) belirlenmiştir.
\end{abstract}

\section{Pest and Beneficial Species on Cherry and Sour Cherry Orchards in Bolu}

\section{Keywords:}

Bolu, cherry, sour cherry, pests, natural enemies

\begin{abstract}
Cherry and sour cherry are economically important fruit varieties with fresh and dry consumption. Due to ecological features of Seben (Bolu), it is the most fruit producing of Bolu province. This study was carried out to determine the pest and beneficial species in the cherry and sour cherry orchards of Seben between 2015 and 2016. Surveys were done every two weeks from the beginning May to the ending October. A result of this study, 16 insect harmful species from 14 families of seven orders and seven beneficial species from three families of three orders were determined in the cherry orchards. Rhagoletis ceraci L. (Diptera: Tephritidae), Myzus cerasi F. (Hemiptera: Aphididae), Drosophila suzukii Matsumura (Diptera: Drosophilidae), Panonychus ulmi (Koch) and Tetranychus urticae Koch (Acarina: Tetranychidae) were found as more common harmful species. Stethorus gilvifrons Muls., Stethorus punctillum Weise, Coccinella septempunctata L. (Coleoptera: Coccinellidae) and Chrysoperla carnea Steph. (Neuroptera: Chrysopidae) were determined as the most common natural enemies.
\end{abstract}




\section{GiRiş}

Kiraz (Prunus avium L.) ve vişne (Prunus cerasus L.) ülkemizde geniş alanlarda yetiştiriciliği yapılan ve ekonomik yönden önemli meyve çeşitleridir. Kiraz ve vişne meyveleri genellikle taze olmakla birlikte, kuru ve dondurulmuş olarak da pastalarda, reçel yapımında ve yemeklerde tüketilmektedir. Kiraz ve vişne ağaçlarının kökleri, kerestesi, kabukları, zamkı, yaprakları, çiçekleri, çekirdeği ve meyve sapları da farklı sektörlerde kullanım alanı bulmaktadır (Kalyoncu ve ark., 2008). Özellikle meyvelerin antioksidan potansiyele sahip olan melatonin maddesini yüksek miktarda içermesi nedeniyle,e başta yaşlılar olmak üzere meyve suyu tüketiminin teşvik edilmesi gerektiği kaydedilmiştir (Pszczola, 2001).

Anavatanı Güney Kafkasya, Hazar Denizi ve Kuzey-Doğu Anadolu olduğu bildirilen kiraz (Özbek, 1978), dünyada en fazla Türkiye, ABD, Özbekistan, Şili, İran, İtalya ve İspanya tarafından üretilmektedir. Dünyada kiraz üretimi 2018 yılında 2.585.523 ton olup, Türkiye 639.000 ton ile en çok üretime sahip olan ülke olmuştur (FAO, 2020). Ülkemizde hemen hemen her ilimizde kiraz üretimi yapılmaktadır. Kiraz üretiminde 2018 yılı verilerine göre ilk sırada yer alan Konya ili, ülke üretiminin \%10.26'sını karşılamakta, İzmir \%9.95'i, Bursa \%6.16'sı, Manisa \%7.29'u ve Amasya \%5.80'i olarak takip etmektedir (Tüik, 2020). Vişnenin anavatanı ise Hazar Denizi ile İstanbul arasındaki Kuzey Anadolu dağları olarak bilinmektedir (Özbek, 1978). En fazla vişne üretimi yapan ülkeler ise Rusya, Ukrayna, Polonya, Türkiye, ABD ve Sırbistan şeklinde sıralanmaktadır. Dünyada vişne üretimi ise 2018 yılında 1.529 .000 ton olup, Türkiye 184.000 ton ile en çok üretim yapan ülkeler arasında dördüncü sırada yer almaktadır (FAO, 2020). Ülkemizde 2018 yılında en çok vişne üretilen iller sırasıyla Afyon, Konya ve Kütahya'nın toplam vişne üretimi ülke üretiminin \%54'ünü oluşturmaktadır (Tüik, 2020). Bolu ilinde yöreye özgü vişne ve kiraz çeşitleri bulunmaktadır. Yöre halkının önemli bir gelir kaynağı olan kiraz ve vişne meyveleri yaş, kuru, hoşaflık ve marmelat üretiminde kullanılmaktadır. Bu ürünler, yerli halkın yanı sıra Bolu ilinin turistik potansiyeli nedeniyle gelen ziyaretçiler tarafından da tercih edilmektedir.

Ülkemizde kiraz ve vişne üretiminde ekonomik kayıplara neden olan önemli zararlı türler bulunmaktadır.. Ülkemizde farklı bölgelerde yürütülen çalışmalarda kiraz ve vişne bahçelerinde zararlı ve faydalı türler belirlenmiştir. Illk olarak Nizamlıoğlu (1957) kirazlarda 28 zararlı tür tespit etmiştir. Daha sonra yapılan çalışmalarda Ege Bölgesi'nde 19 zararlı ve 50 yararlı tür (Ulu ve ark., 1995), Kuzeydoğu Anadolu Bölgesi'nde 43 zararlı ve 28 avcı tür (Özbek ve ark.,1996), Tekirdağ ili ve çevresinde 23 zararlı tür (Özder, 1999), Ulukışla (Niğde)-Pozantı (Adana)'da 86 zararlı ve 21 avcı tür (Ulusoy ve ark., 1999), Elazığ ve Mardin illerinde 36 zararlı, 15 predatör ve 2 parazitoit tür (Çınar ve ark., 2004), Ankara ilinde 21 zararlı, 8 faydalı tür (Özkan ve ark., 2004), Karaman ilinde 15 zararlı ve 9 faydalı tür (Özcan, 2007), Çanakkale ilinde 51 fitofag, 13 predatör ve 6 parazitoit tür (Ertop ve Özpınar, 2011), Diyarbakır ilinde 29 zararlı ve 14 faydalı tür (Kaplan, 2019a) ve son olarak Adana ilinde 26 zararlı türün (Özbek Çatal ve ark., 2020) olduğu kaydedilmiştir. Ayrıca ülkemiz kiraz bahçelerinde familya düzeyinde yapılmış faunistik çalışmalar da bulunmaktadır. Tezcan (1995) Kemalpaşa (İzmir) yöresinde Buprestidae (Coleoptera) familyasından dokuz tür, Tezcan ve Pehlivan (2001) İzmir ve Manisa illerinde Scarabaeidae (Coleoptera) familyasından toplam 17 tür, Tezcan ve Uygun (2003) İmir ve Manisa illerinde Coccinellidae (Coleoptera) familyasından 14 cinse ait 25 tür, Tezcan ve Yıldırım (2004) Vespidae, Sphecidae, Scoliidae, Megachilidae ve Apidae (Hymenoptera) familyasından 18 tür, Özgen ve ark. (2005) Elazı̆̆ ve Mardin illerinde Pentatomidae (Hemiptera) familyasından 6 zararlı tür ve Okyar ve Tezcan (2013) Batı Anadolu Bölgesi'nde Noctuidae (Lepidoptera)'dan 76 tür tespit ettiklerini bildirmişlerdir. Bu çalışmalar incelendiğinde kiraz üretiminde zarar oluşturan en önemli türlerin Kiraz sineği Rhagoletis ceraci L. (Diptera: Tephritidae) ve Elma yaprakbüken Archips rosanus L. (Lepidoptera: Tortricidae) olduğu bildirilirken, Yaprakbitleri, Kırmızıörümcekler, Meyve yazıcı böcekleri, Armut kaplanı ve Bakla zınnı gibi zararlıların da kiraz bahçelerinde sıklıkla zarar oluşturan türler olduğu kaydedilmiştir. Bu türler arasında ana zararlı Kiraz sineği olmakla birlikte bazı türlerde zaman zaman ekonomik kayıplara neden olmaktadır

Bolu ilinin önemli meyve üretimini gerçekleştiren Seben ilçesi kiraz ve vişnelerinde zararlı ve yararlı türleri belirlemeye yönelik bugüne kadar çalışma yürütülmemiştir. Bu çalışma kiraz ve vişne alanlarında zararlı ve faydalı faunanın tespit edildiği temel bir çalışmadır. Bu nedenle elde edilen bulgularla, sonraki çalışmalara ve mücadele programlarına temel oluşturulması amaçlanmıştır.

\section{MATERYAL VE METOT}

Bu çalışma, Bolu ili Seben ilçesinde kiraz ve vişne bahçelerinde zararlı ve yararlı böcek türlerini belirlemek amacıyla yürütülmüştür. Bu amaçla örneklemeler 2015-2016 yılları arasında vejetasyon dönemi boyunca iki haftada bir kez yapılmıştır. Bu bahçelerde örneklemeler Lazarov ve Grigorov (1961) esas alınarak yapılmışır. Örneklemede seçilen her bir ağacın dört yönünden birer adet $50 \mathrm{~cm}$ 'lik dalda kontroller yapılmıştır. Burada 
bulunan yaprak, tomurcuk, çiçek ve meyvelerde ve her ağacın kök boğazı ile gövdesi önce çıplak gözle inceleme yapılmış, böcekler elle veya emgi tüpü (ağız aspiratörü) yardımıyla toplanmıştır. Ayrıca her ağaçtan dört dala toplam 100 defa vurularak $1 \mathrm{~m}^{2}$ lik Steiner hunisi ile örnekleme yapılmıştır. Bu bahçelerde incelemeler esnasında belirlenen yararlı ya da zararlı böcek türlerinin ergin ve ergin öncesi dönemleri, bulundukları bitki kısımlarıyla birlikte öncelikle kağıt, sonra polietilen torbalar içerisine konularak buz kutusu içerisinde laboratuvara getirilmiştir.

Laboratuvara getirilen örnekler ayrılmış ve etiketlenmiştir. Ergin öncesi dönemleri laboratuvarda \%60-70 nem ve $25^{\circ} \mathrm{C}$ sıcaklık, 14:8 (gece:gündüz) koşullarda kültüre alınmış ve erginler elde edilmiştir. Usulüne uygun şekilde iğnelenip, etiketlenen böceklerin bir kısmı koleksiyon çekmecelerine kaldırılırken, diğer kısmı ise konu uzmanlarına teşhis için gönderilmiştir. Bazı örneklerin teşhisleri ise önceden teşhisli materyallerle karşılaştırılarak yapılmıştır. Yumuşak vücutlu böcekler ise \%70'lik alkole alınmış ve bu böceklerin preparatları Düzgüneş (1980) esas alınarak yapılmıştır.

\section{BULGULAR VE TARTIŞMA}

Bolu ili Seben ilçesi kiraz ve vişne bahçelerinde yapılan çalışma sonucunda yedi takıma bağlı 14 familyadan 16 zararlı tür tespit edilmiştir (Çizelge 1). Faydalı türler olarak ise üç takımdan üç familyaya bağlı yedi tür belirlenmiştir (Çizelge 2).

Çizelge 1. Bolu ili Seben ilçesi kiraz ve vişne bahçelerinde belirlenen zararlı türler.

Table 1. Pests of the cherry and sour cherry orchards in Seben of Bolu.

\begin{tabular}{|c|c|c|}
\hline Takım & Familya & Tür \\
\hline \multirow[t]{2}{*}{ Diptera } & Tephritidae & Rhagoletis cerasi L. \\
\hline & Drosophilidae & Drosophila suzukii Matsumura \\
\hline Hemiptera & Aphididae & $\begin{array}{l}\text { Myzus cerasi F. } \\
\text { Myzus persicae Sulz. }\end{array}$ \\
\hline & $\begin{array}{l}\text { Tingidae } \\
\text { Issidae }\end{array}$ & $\begin{array}{l}\text { Stephanitis pyri } \mathrm{F} . \\
\text { Agalmatium sp. }\end{array}$ \\
\hline Acarina & Tetranychidae & $\begin{array}{l}\text { Panonychus ulmi Koch } \\
\text { Tetranychus urticae Koch }\end{array}$ \\
\hline Lepidoptera & $\begin{array}{l}\text { Tortricidae } \\
\text { Lyonetliidae } \\
\end{array}$ & $\begin{array}{l}\text { Archips rosanus L. } \\
\text { Lyonetia clerkella L. }\end{array}$ \\
\hline Hymenoptera & Tenthredinidae & Caliroa cerasi $\mathrm{L}$. \\
\hline Coleoptera & $\begin{array}{l}\text { Scarabaeidae } \\
\text { Scolytidae } \\
\text { Attelabidae } \\
\text { Curculionidae }\end{array}$ & $\begin{array}{l}\text { Tropinota hirta Poda } \\
\text { Scolytus sp. } \\
\text { Rhynchites sp. } \\
\text { Anthonomus sp. }\end{array}$ \\
\hline Thysanoptera & Thripidae & Frankliniella occidentalis Pergande \\
\hline
\end{tabular}

Çizelge 2. Bolu ili Seben ilçesi kiraz ve vişne bahçelerinde belirlenen doğal düşmanlar. Table 2. Natural enemies of the cherry and sour cherry orchards in Seben of Bolu.

\begin{tabular}{|c|c|c|}
\hline Takım & Familya & Tür \\
\hline Coleoptera & Coccinellidae & $\begin{array}{l}\text { Stethorus gilvifrons Muls. } \\
\text { Stethorus punctillum Weise } \\
\text { Coccinella septempunctata L. }\end{array}$ \\
\hline Dermaptera & Forficulidae & $\begin{array}{l}\text { Forficula auricularia } \mathrm{L} . \\
\text { Forficula smyrnensis Serville } \\
\text { Guanchia hincksi Burr }\end{array}$ \\
\hline Neuroptera & Chrysopidae & Chrysoperla carnea Steph. \\
\hline
\end{tabular}

Seben ilçesi kiraz ve vişne bahçelerinde Kiraz sineği $R$. cerasi'nin ana zararlı konumunda olduğu, bunun yanı sıra Noktalı Kanatı Drosophila suzukii Matsumura (Diptera: Drosophilidae) ve Yaprakbitleri Myzus cerasi F. ve M. persicae Sulz. (Hemiptera: Aphididae)'nin de zarara yol açtığı tespit edilmiştir. Bazı bahçelerde ise Tetranychus urticae Koch ve Panonychus ulmi (Koch) (Acarina: Tetranychidae) zaman zaman önemli zararlı türler olarak ortaya çıkmışıır. Ayrıca Elma yaprakbüken A. rosanus, Armut kaplanı Stephanitis pyri F. (Hemiptera: Tingidae) ve Kiraz sülüğü Caliroa cerasi L. (Hymenoptera: Tenthredinidae)'nin yaygın türler olmakla birlikte ekonomik anlamda önemli olmadıkları belirlenmiştir. Kiraz ve vişne bahçelerinde zararlı ve yararlı türleri belirlemek amacıyla ülkemizin farklı illerinde birçok çalışma yürütülmüştür. Ulusoy ve ark. (1999) Ulukışla-Pozantı (Adana)'da M. cerasi, S. pyri, Tropinota hirta (Poda), Cetonia aurata L., Melolontha albida Friv., Polyphylla olivieri Lap., Anoxia orientalis Kryn. 
(Coleoptera: Scarabaeidae), Capnodis tenebrionis L. (Coleoptera: Buprestidae), Scolytus rugulosus Muller (Coleoptera: Scolytidae), Eusomus ovulum Germ., Rhinocyllus sp. (Coleoptera: Curculionidae), Rhynchites bacchus L. (Coleoptera: Rhynchitidae), A. rosanus, C. limacina ve $R$. cerasi türlerinin ekonomik anlamda zararlı olduğunu ve Forficula auricularia L. (Dermaptera: Forficulidae), Chrysoperla carnea Steph. (Neuroptera: Chrysopidae), Coccinella septempunctata L., Adalia bipunctata L. (Coleoptera: Coccinellidae), Metasyrphus corollae F. ve Episryphus balteatus DeGeer (Diptera: Syrphidae) türlerinin ise bölgede en fazla bulunan yararlı türler olduğunu bildirmişlerdir. Çınar ve ark. (2004) Elazığ ve Mardin illerinde S. pyri, M. cerasi, A. rosanus, C. tenebrionis ve S. rugulosus'un ekonomik kayıplara neden olan zararlı türler olduğu ve C. semptempunctata, Synharmonia conglobata L. (Coleoptera: Coccinellidae), M. corollae, C. carnea ve Scolothrips longicornis Priesner (Thysanoptera: Thripidae)'in de bölgede en fazla rastlanılan yararlı türler olduğunu bildirmişlerdir. Özkan ve ark. (2004) Ankara ilinde, $R$. cerasi, Rhynchites sp. ve T. urticae'nin ekonomik anlamda zararlı tür olduğunu belirlemişlerdir. Özcan (2007) Karaman ilinde, en önemli zararlılar olarak Lyonetia clerkella L. (Lepidoptera: Lyonetliidae) ve T. urticae'yi ve doğal düşmanlardan ise S. gilvifrons'u en yaygın tür olarak bildirmiştir. Ertop ve Özpınar (2011) Çanakkale ilinde çalışmada önemli bulunan zararlı türlerden R. cerasi, Lymantria dispar L. (Lepidoptera: Lymantriidae), Cydia molesta Busck (Lepidoptera: Tortricidae) ve T. hirta'nın popülasyon değişimlerini takip etmişlerdir. Kaplan (2019a) Diyarbakır ilinde A. rosanus, R. cerasi, T. hirta, S. pyri, M. cerasi, C. tenebrionis, S. rugulosus ve T. urticae'nin ekonomik yönden zararlı olduğunu ve C. semptempunctata, S. conglobata, Scymnus pallipediformis Gunther (Coleoptera: Coccinellidae), M. corollae ve C. carnea'nın en fazla görülen yararlı türler olduğunu bildirmiştir. Son olarak, Özbek Çatal ve ark. (2020) Adana ilinde R. cerasi, D. suzukii, T. hirta, S. rugulosus, M. cerasi, A. rosanus ve S. pyri'nin bölgede yaygın olarak bulunduğu ve zarar yaptığını belirlemişlerdir.

Yine ülkemizde kiraz bahçelerinde familya bazlı yapılan faunistik çalışmalarda ise Tezcan (1995) Kemalpaşa (İzmir) yöresinde Buprestidae (Coleoptera) familyasında tespit ettiği dokuz tür arasından C. tenebrionis, $C$. carbonaria, Agrilus roscidus Kiesw. ve Sphenoptera simulatrix Reitter (Coleoptera: Buprestidae) türlerinin daha fazla bulunduğunu bildirmiştir. Tezcan ve Pehlivan (2001) İzmir ve Manisa illerinde Oxythyrea cinctella Schm. ve Caccobius histeroides Mén. (Coleoptera: Scarabaeidae)'in en çok bulunan türler olduğunu belirlemişlerdir. Tezcan ve Uygun (2003) İzmir ve Manisa illerinde tespit ettikleri Coccinellidae (Coleoptera) familyası türler arasında Stethorus gilvifrons Muls., Scymnus rubromaculatus Goeze ve S. subvillosus Goeze'un daha fazla olduğunu bildirmişlerdir. Tezcan ve Yıldırım (2004) yürüttükleri fauna çalışmasında Vespula germanica F. Vespa orientalis L., Polistes nimphus Christ, P. dominulus Christ (Hymenoptera: Vespidae) ve Apis mellifera L. (Hymenoptera: Apidae) türlerinin daha yaygın bulunduğunu bildirmişlerdir.

Bolu ili Seben ilçesinde yaptığımız çalışma ve genel olarak kiraz ve vişne bahçelerinde önceki yıllarda yapılan çalışmalar değerlendirildiğinde, ekonomik anlamda zararlı olan türlerin benzerlik gösterdiği anlaşılmaktadır. Yapılan çalışmalarda ülkemizde kiraz ve vişne bahçelerinde en fazla zararı belirlenen türlerin $R$. cerasi, M. cerasi, $A$. rosanus, S. pyri, T. hirta, Scolytus sp. ve T. urticae olduğu bildirilmiştir. Ancak Seben ilçesinde yaptığımız çalışma ile Özbek Çatal ve ark. (2020)'nın Adana ilinde yaptığı çalışmada elde edilen bulgular oldukça benzerlik göstermektedir ve önceki yıllarda yapılan çalışmalara ek olarak bu iki çalışmada kiraz ve vişne bahçelerinde zararlı tür olarak D. suzukii tespit edilmiştir. Polifag bir karantina zararlısı olan $D$. suzukii oldukça istilacı bir tür olup, ülkemizde ilk olarak 2014 yılında Erzurum ilinde (Orhan ve ark., 2016), 2015 yılında Ankara ilinde (Önder ve ark., 2016), 2016 yılında Bolu ve Düzce illerinde (Kaçar and Koca, 2017: Kaçar, 2020) ve 2018 yılında ise Çanakkale ilinde (Efil, 2018) tespit edildiği bildirilmiştir.

Seben ilçesi kiraz ve vişne bahçelerinde tespit edilen faydalı türler ise S. gilvifrons, S. punctillum, C. septempunctata ve $C$. carnea en yaygın türler olarak belirlenmiştir. Coccinellidae birçok predatör türe sahip olması sebebiyle tarımsal anlamda önemli familyalardan biridir. Faydalı Coccinellid larva ve erginleri beyazsinek, yaprakbiti, kabuklubit, koşnil, bazı küçük arthropodlar, akarlar ve fungus miselleriyle beslendikleri bildirilmiştir (Uygun, 1981; Yiğit ve Uygun, 1982). Chrysoperla türlerinin ise dünyanın birçok yerinde farklı tarım alanlarında yaygın türler olduğu belirtilmiş (Ridgway ve Jones, 1968; Stark ve Whitford, 1987) ve C. carnea'nın esas olarak yaprakbitleriyle beslenmekle birlikte hemipter ergin ve nimfleri, lepidopter larva ve yumurtaları, beyazsinekler, kabuklubitler, thripsler, psyllidler ve bazı akarlarla beslenen polifag bir avcı olduğu bildirilmiştir (Şengonca, 1980; Kaya ve Öncüer, 1988). Ayrıca bu çalışmada Forficulidae familyasına bağlı türler de tespit edilmiştir. Forficulid türleri polifag ve omnivor türler olup, genellikle bitki materyalleri ile beslenmelerinin yanı sıra yaprakbitleri, kabuklu bitler, örümcekler, akarlar, bazı böceklerin larva ve yumurtaları ve ölü böcekler ile beslenerek (Haas ve Henderickx, 2002; Maher ve Logan, 2007; Tezcan ve Kocarek, 2009; Kaçar ve Nishikawa, 2014; Nishikawa ve Kaçar, 2018) zararlı türlerin popülasyonlarının artmasını engellemek suretiyle fayda sağlamaktadırlar. 


\section{Kiraz ve Vişne Bahçelerinde Önemli Görülen Türlerin Kısa Biyoekolojileri \\ Kiraz Sineği Rhagoletis cerasi}

Seben ilçesi kiraz ve vişne bahçelerinde $R$. cerasi en yaygın tür olarak belirlenmiştir. Zümreoğlu (1986) Kiraz sineği'nin ülkemizde kiraz yetiştiriciliği yapılan hemen hemen her yerde kirazın ana zararlısı konumunda olduğunu bildirmiştir. Zararlı, mayıs ayı sonralarında kiraz bahçelerinde görülmeye başlanmış ve haziran ayında yoğunluğunu arttırdığı tespit edilmiştir. Zararlının yoğun olduğu yerlerde larva zararı nedeniyle meyve dökümlerine neden olduğu belirlenmiştir. Ulusoy ve ark. (1999) Ulukışla-Pozantı yöresinde Kiraz sineğinin mayıs ayı sonlarında ortaya çıkmaya başladığını ve ağustos ayı ortalarına kadar erginlerini tespit ettiklerini bildirmişlerdir. Tezcan ve Gülperçin (2000) Manisa ve İzmir illerinde nisan ayı sonunda erginlerin ortaya çıktığını popülasyonun haziran ayı ortalarına doğru azalmaya başladığını bildirmişlerdir. Çanakkale ve Elazığ ili kiraz bahçelerinde Kiraz sineği erginlerinin mayıs ayı başından haziran ayı ortasına kadar görüldüğünü tespit etmişlerdir (Ertop ve Özpınar, 2011; Kaplan, 2019b).

\section{Kiraz Siyah Yaprakbiti Myzus cerasi ve Şeftali Yaprakbiti Myzus persicae}

Myzus cerasi ve M. persicae, Seben ilçesi kiraz ve vişne bahçelerinde yaygın olarak bulunan türlerden biridir. Kiraz siyah yaprakbiti ve şeftali yaprak bitinin ülkemizin hemen her bölgesinde bulunduğu bildirilmiştir (Anonim, 2017). Genç sürgün ve yapraklarda beslenerek zarara neden olduğu, yağışlı geçen aylardan sonra yapraklarda kıvrılmalara ve fumajine neden olduğu gözlemlenmiştir. Bu türlerin, iklim koşullarına bağlı olarak mayıs ayından itibaren görülmeye başlanmış ve haziran ayının ikinci yarısında en yüksek popülasyona ulaştığı belirlenmiştir. Çınar ve ark. (2004) Elazığ ve Mardin illerinde, Kaplan (2019a) Diyarbakır ilinde Kiraz siyah yaprakbiti'nin nisan ile eylül ayları arasında görüldügünü bildirmişleridir. Özbek Çatal ve ark. (2020) ise Adana ilinde nisan ayının sonlarından itibaren bahçelerde tespit etmişlerdir.

\section{Kırmıı̈örümcekler Tetranychus urticae ve Panonychus ulmi}

Kırmızı̈rümcekler, Seben ilçesi kiraz ve vişne bahçelerinde yaygın olarak bulunmakta olup, haziran ayının ilk haftasından itibaren zararı görülmeye başlanmış, temmuz-ağustos aylarında popülasyonlarının arttığı ve en yüksek popülasyon yoğunluğuna ise ağustos ayının son haftasında ulaştığı tespit edilmiştir. Bu zararılıara ekim ayının ilk yarısına kadar yapraklarda rastlanmıştır. Bu türlerin belirlendiği yapraklarda beslenmesi sonucu zarar yaptığı ve yapraklarda önce beyaz, sonra sarı kahverengi lekeler meydana geldiği gözlemlenmiştir. Ulusoy ve ark. (1999), kirazlarda zararlı olan akar türlerinin mayıs-haziran aylarında görülmesine karşın, esas olarak temmuz ve ağustos aylarında yüksek popülasyonlar oluşturarak önemli zarar meydana getirdiğini bildirmişlerdir. Ayrıca, akarların kiraz ağaçlarındaki zararının yapraklarda ve bir sonraki yılın çiçek tomurcuklarında görüldüğünü, en önemli zararının ise yüksek popülasyon yoğunluklarında bir sonraki yılın meyve çiçeğini oluşturacak tomurcuklarda beslenmesi sonucu meydana geldiğini belirtmişlerdir.

\section{Kanadı Noktalı Sirke Sineği Drosophila suzukii}

Drosophila suzukii, Seben ilçesi kiraz ve vişne alanlarında yaygın olarak bulunan türlerden biridir. Zararlı, olgunlaşmış sağlıklı meyvelerde ve yere düşmüş, çürümekte olan meyvelerde beslenmektedir. Erginler yumurtalarını bırakmak için ovipozitörleriyle sağlam meyvelerde zarara neden olmaktadırlar. Yumurtadan çıkan larvalar meyve içinde beslenmek suretiyle yumuşama ve çürümeye sonucu meyvelerde döküm meydana getirmektedirler. Bu tür esas olarak yumuşak dokulu meyvelere zarar veren polifag bir zararlıdır (Lee ve ark., 2011). Bu türün dişileri, ovipositörlerinin dişli yapısı nedeniyle sağlam meyvelerde zarara neden olduğu bildirilmiştir (Sasaki ve Sato, 1995). Böylelikle sağlam meyvelerde fiziksel zarar oluşturması sonucu sekonder patojen enfeksiyonlarına yol açarak meyve üretiminde \%30-100 oranında verim kaybına neden olduğu kaydedilmiştir (Bolda ve ark., 2010). Bu türün benzeri çalışmalarda Adana, Bolu ve Düzce ili kiraz bahçelerinde de tespit edildiği ve bu bahçelerde kirazlarda ekonomik ölçüde zarar meydana getirdiği bildirilmiştir (Kaçar, 2020; Özbek Çatal ve ark., 2020).

\section{Elma Yaprakbüken Archips rosanus}

Elma yaprakbükeni, vişne ve kiraz bahçelerinde daha az yaygın olan türlerdendir. Zararlının larvaları, meyve ağaçlarının birkaç adet yaprağını salgıladığı ipeksi ağlarla birbirine bağlamaktadır. Larva tek bir yaprakta ise yaprağı rulo gibi sarmaktadır. Özder (1999) Tekirdağ ilinde, Ulusoy ve ark. (1999) ise Adana ve Niğde illerinde, Ertop ve Özpınar (2011) Çanakkale ilinde ve Kaplan (2019a) ise Diyarbakır ilinde zararlının kiraz bahçelerinde yaygın ve önemli bir tür olduğunu bildirmişlerdir. Ankara ilinde yapılan bir çalışmada ise zararlının vişnede ekonomik düzeyde zararlı olmadığı (Özkan ve ark., 2004), Elazığ ve Mardin illerinde ise zararlının popülasyon 
yoğunluğunun yüksek olduğu kiraz bahçelerinde tüm yapraklara zarar vererek meyve ağaçlarında verim kaybına neden olduğu bildirilmiştir (Çınar ve ark., 2004). Özbek Çatal ve ark. (2020) ise A. rosanus'un Adana bölgesinde yaygın görülen ve zarar yapan bir tür olduğunu, ancak ekonomik zarar eşiğine ulaşmadığı için üreticiler tarafından bu zararlıya karşı mücadele yapılmadığını bildirmişlerdir.

\section{Armut Kaplanı Stephanitis pyri}

Stephanitis pyri, kiraz ve vişne bahçelerinde mayıs ayı ile eylül ayları arasında tespit edilmiş, ağustos ayının son haftası en yoğun olduğu dönem olarak belirlenmiştir. Zararlının nimf ve erginleri kiraz yapraklarında beslenmesi sonucu yaprakların alt yüzeyinde pislik ve artıkları ile kaplanmasına neden olmaktadır. Çınar ve ark. (2004) bu zararlıyı Elazığ ve Mardin illerinde nisan-eylül aylarında, Kaplan (2019a) ise Diyarbakır ilinde mayıs-eylül aylarında tespit ettiklerini bildirmişlerdir. Ayrıca Çam (1993), söz konusu zararlının Tokat ili kiraz bahçelerinde yaygın olarak bulunduğunu bildirmiştir.

\section{Kiraz Sülüğ̈̈ Caliroa cerasi}

Kiraz sülüğü haziran ayının ortalarından sonuna kadar görülmeye devam edilmiştir. Zararlının larvaları yaprakların üst epidermisi ile beslenmesi sonucu yapraklar elek gibi bir görünüm oluşturduğu görülmüştür. Erzurum ilinde yapılan çalışmada Kiraz sülüğü'nün ilk ergin çıkışının haziran ayında başladığını ve ağustos ayının ilk yarısında ise ikinci döle ait erginlerin görüldüğü tespit edilmiştir. Ayrıca zarar oranının \%87'lere kadar ulaştığı bildirilmiştir (Çalmaşur, 2007).

\section{Bakla Zınnı Tropinota hirta}

Tropinota hirta, Seben ilçesi kiraz ve vişne bahçelerinde nadir rastlanılan bir tür olup, yalnızca mayıs ayı başında erginler tespit edilmiştir. Ertop ve Özpınar (2011) Çanakkale ilinde nisan ayından mayıs ayı başına kadar bu zararlının erginlerini tespit etmişlerdir. Kaplan (2019a) ise Diyarbakır ilinde en yüksek yoğunluğuna nisan ayı ortasında ulaştığını bildirmiştir. Zararının erginlerinin, meyve ağaçlarının çiçeklerinin dişi ve erkek organlarını, genç yapraklarını, hatta tomurcuk ve meyvelerini yiyerek zarar verdikleri bildirilmiştir (Anonim, 2017).

\section{Meyve Yazıcı Böcekleri Scolytus spp.}

Meyve yazıcı böcekleri, Seben ilçesi kiraz ve vişne bahçelerinde daha az görülen türlerdendir. Bu zararlılar, kiraz ağaçlarının sekonder bir zararısı olup genellikle zayıf düşmüş ağaçlarda zarar oluşturmaktadırlar. Yazıcı böceklerin meyve ağaçlarının sürgün ve dallarında kabuk altında galeriler açması zararı sonucu, yaprak ve meyveleri taşıyan buketlerin kuruyarak meyve veremediği ve bu şekildeki kurumalarla gerek o yıl gerekse sonraki yıllarda meyve ve yaprak verecek gözlerde önemli kayıplar oluştuğu kaydedilmiştir (Tezcan ve Civelek, 1996). Ulusoy ve ark. (1999), Niğde ve Adana illerinde kiraz bahçelerinde S. rugulosus'un yüksek popülasyon yoğunluklarında sağlıklı ağaçlara da saldırdığını, zamanında önlem alınmayan ağaçların önce genç dallarında, daha sonra ana dallarında ve gövdesinde kurumalar meydana getirdiğini belirlemişlerdir. Bozkurt ve Özdem (2013), Orta Anadolu Bölgesi (Isparta, Afyon, Çankııı)'nde S. rugulosus erginlerinin mayıs ayı sonu ile ekim ayı başlarına kadar olan dönemde belirlemişler ve ergin popülasyonunun haziran ayında tepe noktasına ulaştığını bildirmişlerdir.

\section{Kiraz Yaprak Galeri Güvesi Lyonetia clerkella}

Lyonetia clerkella, kiraz bahçelerinde daha az sayıda bulunmuştur. Bu zararlı, ağustos ayının başları ile eylül ayı sonlarına kadar kiraz bahçelerinde tespit edilmiştir. Özcan (2007) Karaman ilinde L. clerkella erginlerini mayıs-eylül ayları arasındaki dönemlerde kiraz bahçelerinde bulunduğunu belirlemiştir. Bu zararlı, yapraklarda düzensiz galeriler açarak beslenmekte ve değişik uzunluklarda galerileri beyazımsı veya gri alanlar olarak dışarıdan görülebilmektedir. Rather ve ark. (2017) söz konusu zararlının yaprak epidermisine zarar vermeden mezofili tükettiğini bildirmişlerdir.

\section{Çiçek Thripsi Frankliniella occidentalis}

Frankliniella occidentalis, Seben ilçesi kiraz bahçelerinde az tespit edilen türlerdendir. Thysanoptera takımına bağlı türlerin çiçek tomurcuğu, çiçek ve genç meyveler gibi meyve organlarında beslenmesi sonucu dökülmelere, şekil bozukluklarına ve özellikle meyve dokusu üzerinde sert yara dokusuna neden oldukları bildirilmiştir (Atakan, 2009). Ülkemizde kiraz üretim alanlarında Thysanoptera takımına bağlı türler hakkında detaylı çalışmaların bulunmadığını ifade eden Uzun ve ark. (2015), Isparta ilinde çalışma yaptıkları kiraz bahçelerinin \%13.54'ünde $F$. occidentalis'i tespit ederek en yoğun thrips türleri arasında olduğunu bildirmişlerdir. 


\section{SONUÇ}

Bolu ili Seben ilçesi kiraz ve vişne bahçelerinde yapılan çalışma sonucunda 16 zararlı tür ve yedi faydalı tür belirlenmiştir. Tespit edilen zararlı türlerden $R$. ceraci, $M$. cerasi, $D$. suzukii, $P$. ulmi ve $T$. urticae türleri kiraz bahçelerinde yaygın ve sık belirlenen türler olduğu bulunmuştur. Doğal düşmanlardan en yaygın türler olarak ise S. gilvifrons, S. punctillum, C. septempunctata ve C. carnea türleri tespit edilmiştir. Kirazın ana zararlısı olan ve kirazda ekonomik ölçüde zarar meydana getiren $R$. cerasi ve yaygın türlerden olan $D$. suzukii, meyve verim ve kalitesini olumsuz etkilemekte ve ürünlerin pazar değerini düşürmektedirler. Söz konusu her iki zararlının kontrolü için meyveler olgunlaştığı zaman geciktirilmeden hasata başlanmalı, hasattan sonra ağaç üzerinde meyve bırakılmamalı ve yere düşen meyveler toplanarak gömülerek imha edilmelidir. Ayrıca her iki zararlı için kitle tuzaklama çalışmaları uygulanarak popülasyonları azaltılabilir. Kimyasal mücadeleye intiyaç duyulması halinde ise doğal düşmanların takip edilerek ve zararlının ergin çıkış zamanları dikkate alınarak ilaçlama yapılmalıdır.

Bolu ilinin Seben ilçesi, meyve yetiştiriciliği açısından mikro-klima iklim yapısı nedeniyle meyve üretimi açısından uygun bir ekolojiye sahiptir ve meyve çeşitlerinin yetiştiriciliğinde ön plana çıkmaktadır. Ayrıca meyveciliğin gelişmesi bakımından yeni yatıımlar yapılmıştır. Üreticilerin büyük çoğunluğu zararlılara karşı kimyasal mücadele uygulamaktadır. Pestisit kullanımıla beraber birçok sorun meydana gelmekte ve ekosistemdeki çeşitlilik önemli oranda etkilenerek doğal dengenin bozulmasına sebep olmaktadır. Bu sebeple, zararlılarla mücadelede kullanılacak kimyasalların çevre dostu olmasına ve doğal düşmanlara zarar vermemesine dikkat edilmelidir. Ayrıca kimyasalların olumsuz etkilerini en aza indirecek alternatif mücadele metotlarına da intiyaç duyulmaktadır. Kimyasal mücadeleye alternatif olarak entegre zararlı yönetimi programlarının geliştirilebilmesi için zararlı türlerin doğal düşmanları ile popülasyon dinamiklerinin ortaya konulması ve önemli doğal düşmanların etkinliklerini tespit etmeye yönelik çalışmaların yapılmalıdır. Bu kapsamda da özel bir ekoloji ve coğrafyaya sahip olan ilçede organik meyve üretimini teşvik etmek amacıyla biyolojik mücadele ile biyoteknik mücadele yöntemleri dikkate alınmalıdır. Bu çalışma sonuçları, daha sonra yürütülecek detaylı çalışmalar ile kiraz bahçelerinde gerçekleştirilecek mücadele programlarının oluşturulmasına alt yapı sağlayacaktır.

\section{ÇIKAR ÇATIŞMASI}

Yazarlar arasında herhangi bir çıkar çatışması bulunmamaktadır.

\section{YAZAR KATKISI}

Arazi çalışmaları ve makalenin yazımı her iki yazarın katkıları ile gerçekleştirilmiştir.

\section{TEŞEKKÜR}

Coccinellidae türlerinin teşhisi için Dr. Öğr. Üyesi Derya Şenal (Bilecik Şeyh Edebali Üniversitesi, Bilecik) ve Forficulidae türlerinin teşhisi için Masaru Nishikawa (Ehime University, Japan)'ya teşekkür ederiz.

\section{KAYNAKLAR}

Anonim (2017). Kiraz ve Vişne Entegre Mücadele Teknik Talimatı. T.C. Gıda, Tarım ve Hayvancılık Bakanlığı, Tarımsal Araştırmalar ve Politikalar Genel Müdürlüğü, Ankara.

Atakan, E. (2009). Adana ve çevresinde yenidünya bahçelerinde bulunan Thysanoptera (Trips) türleriyle avcı böceklerin populasyon değişimleri ve trips zararı üzerine araştırmalar. Alatarım, 8(2), 1-7.

Bolda, M., Goodhue, R. E., \& Zalom, F. G. (2010). Spotted wing drosophila: potential economic impact of a newly established pest. Agricultural and Resource Economics Update, 13(3), 5-8.

Bozkurt, V., \& Özdem, A. (2013). Orta Anadolu Bölgesinde kiraz ağaçlarında zararlı meyve yazıcıböcek türlerinin (Coleoptera: Curculionidae: Scolytinae) tespiti, yoğunlukları ile önemli türün biyolojik kriterlerinin belirlenmesi. Bitki Koruma Bülteni, 53(2), 65-76.

Çalmaşur, Ö. (2007). Erzurum ilinde kiraz sülüğü Caliroa cerasi (Linnaeus, 1758) (Hymenoptera: Tenthredinidae)'nin biyolojisi ve zararı. Atatürk Üniversitesi Ziraat Fakültesi Dergisi, 38(1), 59-63.

Çam, H. (1993). Tokat ve çevresinde kiraz, vişne ve idris ağaçlarında bulunan Heteroptera türleri üzerinde araştırmalar. Gaziosmanpaşa Üniversitesi Ziraat Fakültesi Dergisi, 10, 32-42. 
Çınar, M., Çimen, İ., \& Bolu, H. (2004). Elazığ ve Mardin illeri kiraz ağaçlarında zararlı olan türler, doğal düşmanları ve önemlileri üzerinde gözlemler. Türkiye Entomoloji Dergisi, 28(3), 213-220.

Düzgüneş, Z. (1980). Küçük Arthropodların Toplanması, Saklanması ve Mikroskobik Prepatlarının Hazırlanması. Gıda Tarım Hayvancılık Bakanlığı Zirai Mücadele Zirai Karantina Genel Müdürlüğü Yayınları, Ankara.

Efil, L. (2018). Çanakkale ili çilek alanlarında yeni bir zararlı Drosophila suzukii (Matsumura) (Diptera: Drosophilidae)'nin yayılış alanları ve bulaşıklığı. Türk Tarım ve Doğa Bilimleri Dergisi, 5(3), 280-284.

Ertop, S., \& Özpınar, A. (2011). Çanakkale ili kiraz ağaçlarındaki fitofag ve yararlı türler ile bazı önemli zararlıların popülasyon değişimi. Türkiye Entomoloji Bülteni, 1(2), 109-118.

FAO. (2020). Bitkisel üretim istatistikleri http://www.fao.org/faostat/en/\#data/QC. Erişim tarihi: 02 Mayıs 2020.

Haas, F., \& Henderickx, H. (2002). Dermaptera from Cyprus and Turkey. Beitraege zur Entomologie Keltern, 52(1), $235-239$.

Kaçar, G., \& Koca, A. S. (2017). First recording of spotted wing drosophila in Bolu and Düzce of Turkey and moleculer identification, II. International Iğdır Symposium, Iğdır, Turkey.

Kaçar, G., \& Nishikawa, M. (2014). Forficulidae fauna of olive orchards in the South Eastern and Mediterranean Regions of Turkey. Journal of the Entomological Research Society, 16(1), 27-35.

Kaçar, G. (2020). New records of the parasitoids of Drosophila suzukii: molecular identification in newly invaded areas in Turkey. Turkish Journal of Entomology, 44(1), 71-79.

Kalyoncu, İ. H., Ersoy, N., \& Kurt, H. (2008). Kiraz (Prunus avium L.) yeşil uç çeliklerinin köklenmesi üzerine farklı ıba dozları ve nem seviyelerinin etkileri. Selçuk Tarım Bilimleri Dergisi, 22(46), 68-72.

Kaplan, M. (2019a). Diyarbakır ili bazı kiraz bahçelerinde bulunan zararlı ve faydalı böcek türleri ile bazı önemli zararlı türlerin doğada görülme zamanı. Avrupa Bilim ve Teknoloji Dergisi, 17, 283-289.

Kaplan, M. (2019b). Elazığ ili kiraz üretim alanlarında kiraz sineği (Rhagoletis cerasi L.) (Diptera: Tephritidae)'nin yayılışı, doğaya çıkış zamanı, popülasyon gelişimi ve bulaşıklık oranını belirlenmesi. Avrupa Bilim ve Teknoloji Dergisi, 16, 363-366.

Kaya Ü., \& Öncüer C. (1988). Investigations on the effect of two different food to the biology of Chrysoperla carnea (Steph.) (Neuroptera:Chrysopidae) which are reared in laboratory. Turkish Journal of Entomology, 12(3), 151-159.

Lazarov, A., \& Grigorov, P. (1961). Karantina Na Rastenijata Zemizdat, Sofia, Bulgaria. 258 pp

Lee, J. C., Bruck, D. J., Curry, H., Edwards, D., Haviland, D. R., van Steenwyk, R. A., \& Yorgey, B. M. (2011). The susceptibility of small fruits and cherries to the spotted-wing drosophila, Drosophila suzukii. Pest Management Science, 67, $1358-1367$.

Maher, B. J., \& Logan, D. P. (2007). European earwigs, Forficula auricularia, and predation of scale insects in organic and conventionally managed kiwifruit. New Zealand Plant Protection, 60, 249-253.

Nishikawa, M., \& Kaçar, G. (2018). Apterygida albipennis (Megerle von Mühlfeld, 1825) (Dermaptera: Forficulidae: Forficulinae), a new record for Turkey, with a note on the nomenclatural validity of the species name. Japanese Journal of Systematic Entomology, 24(2), 238-242.

Nizamlıŏlu, K. (1957). Türkiye meyve ağacı zararlıları ve mücadelesi. Koruma Tarım ilaçları AŞ Neşriyatı, 5, $134-154$.

Okyar, Z., \& Tezcan, S. (2013). On the noctuid fauna (Lepidoptera: Noctuidae) of ecological cherry orchards in western Turkey. Zoology in the Middle East, 22(1), 95-102.

Orhan, A., Aslantaş, R., Önder, B. S., \& Tozlu, G. (2016). First record of the invasive vinegar fly Drosophila suzukii (Matsumura) (Diptera: Drosophilidae) from eastern Turkey. Turkish Journal of Zoology, 40, 290-293.

Önder, S., Ufuk, U., Orhan, R., Tozlu, G. \& Aslantaş, B. (2016). Anadolu'da yeni bir meyve zararlısı olan Drosophila suzukii'nin kolanizasyon senaryosu. 23. Ulusal Biyoloji Kongresi, Gaziantep, Türkiye.

Özbek, S. (1978). Özel Meyvecilik. Çukurova Üniversitesi Ziraat Fakültesi Yayınları, 128, Ders Kitabı: 11, Adana.

Özbek, H., Güçlü, Ş., \& Hayat, R. (1996). Kuzeydoğu tarım bölgelerinde taş çekirdekli meyve ağaçlarında bulunan fitofag ve predatör böcek türleri. Turkish Journal of Agriculture and Forestry, 20, 267-282.

Özbek Çatal, B., Amangeldi, Z., Çalışkan Keçe, A. F., \& Ulusoy, M. R. (2020). Adana ili kiraz yetiştiriciliği yapılan alanlarda belirlenen zararlı böcek türleri. Avrupa Bilim ve Teknoloji Dergisi, 18, 332-337.

Özcan, R. (2007). Başyayla (Karaman) ilçesinde kiraz ağaçlarında bulunan zararlı böcekler, akarlar ve doğal düşmanlarının tespiti üzerine araştırmalar. Yüksek Lisans Tezi, Selçuk Üniversitesi, Fen Bilimleri Enstitüsü, Konya.

Özder, N., (1999). Tekirdağ ilinde kiraz bahçelerinde bulunan doğal düşmanlar ve bunlardan yumurta parazitoiti Trichogramma cacoeciae March. (Hym.: Trichogrammatidae)'nin yaprak büken türlerinde (Lep.: Tortricidae) doğal etkinliği üzerinde araştırmalar. Türkiye 4. Biyolojik Mücadele Kongresi, Adana, Türkiye. 
Özgen, I., Gözüaçık, C., Karsavuran, Y., \& Fent, M. (2005). Doğu ve Güneydoğu Anadolu Bölgesi'nde antepfıstığı, kayısı, kiraz ve zeytin ağaçlarında bulunan Pentatomidae (Heteroptera). Ege Üniversitesi Ziraat Fakültesi Dergisi, 42(2), 35-43.

Özkan, C., Gürkan, O., \& Hancıoğlu, Ö. (2004). Çubuk (Ankara) ilçesi vişne ağaçlarında zararlı olan türler, doğal düşmanları ve önemlileri üzerinde gözlemler. Tarım Bilimleri Dergisi, 11(1), 57-59.

Pszczola, D. E. (2001). Antioxidants: from preserving food quality to quality of life. Food Technology, 55, 51-59.

Rather, S., Buhroo, A. A., \& Khanday, A. L. (2017). Occurrence of eulophid parasitoids on apple leaf miner Lyonetia clerkella Linn. (Lepidoptera: Lyonetiidae) in Kashmir. International Journal of Entomology Research, 2(6), 39-43.

Ridgway, R. L., \& Jones, S. L. (1968). Field cage-releases of Chrysopa carnea for supression of population of the bollworm and the tobacco budworm on cotton. Journal of Economic Entomology, 61(4), 892-897.

Sasaki, M., \& Sato, R. (1995). Bionomics of the cherry drosophila, Drosophila suzukii Matsumura (Diptera: Drosophilidae) in Fukushima Prefecture (Japan). Annual Report of the Society of Plant Protection of North Japan, 46, 164-172.

Stark S. B., \& Whitford F. (1987). Functional response of Chrysopa carnea (Neuroptera: Chrysopidae) larvae feeding on Heliothis virescens (Lep.: Noctuidae) eggs on cotton in field cages. Entomophaga, 12(5), 521-527 pp.

Şengonca, Ç. (1980). Türkiye Chrysopidae (Neuroptera) Faunası Üzerinde Sistematik ve Taksonomik Araştırmalar. T.C. Gıda Tarım ve Hayvancılık Bakanlığı Zirai Mücadele ve Zirai Karanatina Genel Müdürlüğü Yayınları, Ankara, $138 \mathrm{~s}$.

Tezcan, S. (1995). Kemalpaşa (İzmir) yöresi kiraz ağaçlarında zararlı Buprestidae (Coleoptera) familyası türleri üzerinde araştırmalar. Türkiye Entomoloji Dergisi, 19(3), 221-230.

Tezcan, S., \& Civelek, H. S. (1996). Kemalpaşa (İzmir) yöresi kiraz ağaçlarında zararlı Scolytus rugulosus'un yayılışı, biyolojisi ve zararı üzerinde araştırmalar. Türkiye III. Entomoloji Kongresi, Ankara.

Tezcan, S., \& Gülperçin, N. (2000). İzmir ve Manisa illeri ekolojik kiraz üretim bahçelerinin ana zararlılarından Kiraz sineği (Rhagoletis cerasi L.) (Diptera: Tephritidae) ile savaşta sarı yapışkan tuzaklardan yararlanma olanakları. Türkiye 4. Entomoloji Kongresi, Aydın.

Tezcan, S. \& Pehlivan, E. (2001). İzmir ve Manisa illeri ekolojik kiraz üretim bahçelerinin faunası üzerinde araştırmalar: Lucanoidea ve Scarabaeoidea (Coleoptera) türleri üzerinde bir değerlendirme. Ege Üniversitesi, Ziraat Fakültesi Dergisi, $38(2-3), 31-37$.

Tezcan, S., \& Uygun, N. (2003). İzmir ve Manisa yöresi ekolojik kiraz üretim bahçelerinde saptanan Coccinellidae (Coleoptera) türleri üzerinde bir değerlendirme. Türkiye Entomoloji Dergisi, 27(1), 73-79.

Tezcan, S., \& Yıldırım, E. (2004). On the Vespidae, Sphecidae, Scoliidae, Megachilidae and Apidae (Hymenoptera) fauna of ecologically managed cherry orchards in western Turkey. Perspectives on Biosystematics and Biodiversity. Prof. TC Narendran Commemoration Volume, 241-247.

Tezcan, S., \& Kocarek, P. (2009). Dermaptera fauna of the ecologically managed cherry orchards in western Turkey. Munis Entomology \& Zoology Journal, 4(2), 572-576.

TÜiK. (2020). Bitkisel Üretim İstatistikleri. http://tuikapp.tuik.gov.tr/bitkiselapp/bitkisel.zul. Erişim tarihi: 02 Mayıs 2020.

Ulu, O., Önuçar, A., Zümreoğlu, A., Uzun, S., Ergüden, T. M., Aykaç, K., Kılıç, M., Çakır, O., Ceylan, S., \& Koçlu, T. (1995). Kiraz Bahçelerinde Entegre Mücadele Araştırma Geliştirme ve Uygulama Projesi (1990- 1995 Yılları 1. Dilim Sonuç Raporu). Zirai Mücadele Araştırma Enstitüsü, Bornova, İzmir.

Ulusoy, M. R., Vatansever, G., \& Uygun, N. (1999). Ulukışla (Niğde) ve Pozantı (Adana) yöresinde kirazlarda zararlı olan türler, doğal düşmanları ve önemlileri üzerindeki gözlemler. Türkiye Entomoloji Dergisi, 23(2), 111-120.

Uygun, N. (1981). Türkiye Coccinellidae (Coleoptera) Faunası Üzerinde Taksonomik Araştırmalar. Çukurova Üniversitesi Ziraat Fakültesi Yayınları, 157. Bilimsel Araştırma ve İnceleme Tezleri, 48, 110s.

Uzun, A., Tezcan, S., \& Demırözer, O. (2015). Thrips (Thysanoptera) species occurring in cherry orchards in Isparta province of western Turkey. Linzer Biologisch Beiträg, 47(1), 963-968.

Yiğit, A., \& Uygun, N. (1982). Adana, İçel ve Kahramanmaraş illeri elma bahçelerinde zararlı ve yararlı faunanın saptanması üzerinde çalışmalar. Bitki Koruma Bülteni, 22(4), 163-178.

Zümreoğlu, A. (1986). Three years population studies of the European cherry fruit fly (Rhagoletis ceraci L.) with special reference by means of Rebel traps in the western part of Turkey. Proceeding of the CEC/IOBC, Hamburg, Germany. 